\title{
Comparative study between laparoscopic hysterectomy and abdominal hysterectomy for the treatment of early stage endometrial cancer
}

\author{
Rumi Bhattacharjee ${ }^{1}$, Nitin P. Dhungat ${ }^{2}$, Vishal Sheth ${ }^{1 *}$
}

${ }^{1}$ Pramukh Swami medical College. Anand, Gujarat, India

${ }^{2}$ Bombay hospital and Research Institute. Mumbai, Maharashtra, India

Received: 21 August 2020

Accepted: 30 September 2020

\author{
*Correspondence: \\ Dr. Vishal Sheth, \\ E-mail: vishalssheth.89@gmail.com
}

Copyright: (c) the author(s), publisher and licensee Medip Academy. This is an open-access article distributed under the terms of the Creative Commons Attribution Non-Commercial License, which permits unrestricted non-commercial use, distribution, and reproduction in any medium, provided the original work is properly cited.

\begin{abstract}
Background: Aim was to study the feasibility of total laparoscopic pan hysterectomy in patients with early stage endometrial cancer.

Methods: Retrospective and prospective study of 100 patients with clinical early stage endometrial cancer was done in Bombay Hospital \& Research Center over 3 years. 44 patients underwent total laparoscopic hysterectomy while 56 patients underwent abdominal pain hysterectomy. Pelvic lymphadenectomy was performed in patients with myometrium invasion greater than $50 \%$, size of tumor $>2 \mathrm{~cm}$, non-endometroid pathology, Grade 3 .

Results: The mean operating time was 2 hours in the abdominal hysterectomy group and $2.5 \mathrm{hrs}$. In the laparoscopic group. Average blood loss was $350 \mathrm{ml}$ in the abdominal (Abd) group \& $250 \mathrm{ml}$ in the laparoscopic (lap) group. Which was comparable. The abdominal hysterectomy group experienced more postoperative pain than the laparoscopy group. However, cost wise laparoscopy group incurred more expenditure than the abdominal group. Among the postoperative complications, nausea vomiting, paralytic ileus and wound dehiscence were significantly more in the abdominal group as compared to the laparoscopy group.

Conclusions: Morbidity is much less in laparoscopy route compare to open abdominal hysterectomy with equivalent survival.
\end{abstract}

Keywords: Endometrial cancer, Total laparoscopic hysterectomy, Pelvic lymphadenectomy

\section{INTRODUCTION}

Endometrial cancer is the fourth common cancer of the female genital tract. ${ }^{1}$ A study published in the Journal of the National Cancer Institute on October 16, 2017 showed varied incidence rates across the globe. North America and Europe documented the highest incidences while developing countries like India and South Africa showed lower incidences. Advancing age and menopause are high risk factors with $>90 \%$ cancer occurring in women above the age of $50 .^{2,3}$ Women with BMI $>32$ are 4 times at risk. $50 \%$ patients have co morbidity. ${ }^{4} 75 \%$ are diagnosed with stage 1 disease and at least $80 \%$ of women with endometrial cancer can live for 5 years after treatment. ${ }^{1}$ The traditional treatment for endometrial ca has been total abdominal hysterectomy with bilateral salpingo-ophorectomy with or without pelvic and para aortic lymph node dissection and peritoneal washing. But this approach is highly invasive with high morbidity, long hospital stays and wound complications.

The first documented laparoscopic approach was made by Childers and Surwit in $1992 .^{5}$ They performed a laparoscopic surgical staging including laparoscopic assisted vaginal hysterectomy and pelvic and paraaortic lymphadenectomy. Since then numerous authors have documented their experience with laparoscopy. ${ }^{6-8}$ Laparoscopic surgical staging has emerged as a safe and feasible alternative with less morbidity and shorter hospital stay. However morbid obesity, intolerance of 
patients to prolonged GA, trendenlenberg position, long learning curve and surgical expertise preclude the widespread use of laparoscopic approach. ${ }^{9-11}$

\section{METHODS}

A retrospective and prospective observational study of 100 patients with clinical stage 1 endometrial cancer was conducted in the department of Obstetrics and Gynecology, Bombay Hospital and Research Centre over 3 years from January 2010 to December 2012. 44 patients underwent total laparoscopic hysterectomy (TLH) while 56 underwent total abdominal hysterectomy (TAH). The decision for TAH or TLH depended on patient and surgeon preference.

Patients with the following conditions were not considered for TLH: Large bulky uterus $>13 \mathrm{~cm}$, patients with significant cardiopulmonary compromise precluding prolonged trendenlenberg Position, sever hip disease where difficult dorso lithotomy position was anticipated.

Informed consent was obtained from all patients. General patient information and demographic profile were analyzed. All patients underwent routine physical and gynecological examination, pre-operative blood and urine examination and endometrial biopsy to confirm the disease. Pre-operative anesthetic checkups were done. Preoperative imaging with USG and MRI were done for evaluation of the extent of the disease. Patients undergoing the laparoscopic technique were counseled regarding the possibility of conversion to laparotomy if needed. All patients whether assigned to TAH or TLH, were subjected to comprehensive surgical staging comprising of inspection of the intra peritoneal cavity, peritoneal washing, total hysterectomy with $b / 1$ salpingoophorectomy. Pelvic lymphadenectomy was performed in cases where imaging showed disease involvement $>50 \%$ of myometrium.

Morcellation techniques were not used and minimum manipulation of uterus was practiced.

All patients were given antibiotic prophylaxis and DVT (deep vein thrombosis) prophylaxis.

Parameters analyzed were demographic profile, operating time, blood loss, hospital stay, recovery milestones, cost effectiveness, recurrence rate and perioperative complications. Post-operative follows up was scheduled after 1 month and then 3 months for 1 year, where physical and gynecological examination, USG and relevant blood tests were performed.

\section{Statistical analysis}

Statistical analysis was performed using programs available in the SPSS statistical package (SPSS 15.0, Chicago, USA), Microsoft word and excel. Association between screening test and occurrence of disease was calculated by chi-square test. Yate's correction was applied when there was any requirement (i.e. cell numerical value $<5$ ).

\section{RESULTS}

100 patients were included in the study out of which 56 underwent TAH while 44 underwent TLH. Table 1 shows the demographic profile of the patients in the study group.

Table 1: Demographic profile of patients.

\begin{tabular}{|lllllllll|}
\hline Age (years) & \multicolumn{9}{c|}{ Parity $\{$ No $\}$} & Weight (kg) & ABD (\%) & LAP (\%) \\
\hline & ABD (\%) & LAP (\%) & & ABD (\%) & LAP (\%) & & ABD \\
\hline $\mathbf{5 0 - 6 0}$ & $12(21)$ & $12(27)$ & 1 & $8(14)$ & $4(9)$ & $<60$ & $4(7)$ & $4(9)$ \\
\hline $\mathbf{6 0 - 7 0}$ & $12(21)$ & $16(36)$ & 2 & $8(14)$ & $8(18)$ & $60-70$ & $8(14)$ & $8(18)$ \\
\hline $\mathbf{7 0 - 8 0}$ & $16(28)$ & $8(18)$ & 3 & $20(36)$ & $12(27)$ & $70-80$ & $16(28)$ & $20(45)$ \\
\hline$>\mathbf{8 0}$ & $16(28)$ & $8(18)$ & 4 & $16(28)$ & $16(36)$ & $80-90$ & $24(42)$ & $12(27)$ \\
\hline & & & $\geq 5$ & $4(7)$ & $4(9)$ & $>90$ & $4(7)$ & $4(9)$ \\
\hline
\end{tabular}

Age, parity and weight were comparable in both groups. Many patients in both groups belonged to higher order parity. With regards to co-morbidities; obesity, hypertension, diabetes excreta were more in the abdominal group than the laparoscopic group.

With reference to Table 2 the mean operating time was longer in TLH group ( $2.5 \mathrm{hrs}$.) than the abdominal group ( 2 hrs.). However, the mean blood loss was more in the abdominal group $(350 \mathrm{ml})$ in comparison to TLH group $(250 \mathrm{ml})$. Blood loss was estimated by measuring the amount of blood that was collected in the suction apparatus minus irrigation fluid and the weight of preweighted blood-soaked mops. Patients in the abdominal group required a greater number of hospitals stay and more time to recover and assume normal activities. Likewise, pain was more in abdominal group than in TLH group. Pain was analyzed by asking the patients to rate their pain on second post op day from a scale of 1 to 10. Pelvic lymphadenectomy was done in 12 patients of abdominal group and 8 patients of TLH group. Positive lymph nodes were found in 4 among the abdominal group and 2 among the laparoscopic group. Cost wise, the laparoscopic group incurred more expenditure. 
Table 2: Comorbidities distribution in abdominal and laparoscopic route.

\begin{tabular}{|lll|}
\hline Comorbidities & ABD (\%) & LAP (\%) \\
\hline Body mass index $>\mathbf{3 0}$ & $37(66)$ & $26(59)$ \\
\hline Hypertension & $24(43)$ & $16(36)$ \\
\hline Hyperlipidemia & $40(71)$ & $16(36)$ \\
\hline Diabetes melitus & $24(43)$ & $12(27)$ \\
\hline Hypothyroidism & $48(86)$ & $28(63)$ \\
\hline
\end{tabular}

(Table 3) shows the perioperative complications in both groups. Post-operative complications like nausea, vomiting, paralytic ileus and wound dehiscence were more in the abdominal group. One patient in the TLH group had a small hematoma over the left iliac vessel due to injury during trocar insertion. It was observed for 10 minutes and surgery continued without any intervention for the same. Two patients in the abdominal group had bladder injury during uterovesical fold dissection which was managed surgically. Five patients in abdominal group and two in TLH group required intraoperative or postoperative blood transfusion.

Table 3: Comparative clinical outcome in patient underwent surgery either abdominal and laparoscopic route.

\begin{tabular}{|lll|}
\hline Parameters & ABD & LAP \\
\hline Mean operating time (hrs.) & 2 & 2.5 \\
\hline Mean blood loss (ml) & 350 & 250 \\
\hline Avg. hospital Stay (days) & 7 & 4 \\
\hline Pain score (scale of 10) & 6 & 3 \\
\hline Recovery (weeks) & 4 & 2 \\
\hline $\begin{array}{l}\text { Pelvic lymphadenectomy } \\
\text { (no of patients) }\end{array}$ & 12 & 8 \\
\hline $\begin{array}{l}\text { Positive lymph nodes (no of } \\
\text { patients) }\end{array}$ & 4 & 2 \\
\hline Expenditure (average) & $\begin{array}{l}\text { Rs. } \\
30,000 /-\end{array}$ & $\begin{array}{l}\text { Rs. } \\
60,000 /-\end{array}$ \\
\hline
\end{tabular}

None of the patients from TLH group required conversion to laparotomy and no patient had incisional hernia. Recurrence rate which was vault recurrence was similar in both the groups.

\section{DISCUSSION}

Surgical management of early stage endometrial cancer has gradually evolved over the last few decades and much diversification has taken place. Alongside the traditional abdominal approach, advances in the laparoscopic field has allowed total laparoscopic hysterectomy as a feasible alternative. Newer advances include the robotic approach and is under much speculation.

Advantages of the abdominal approach include less operative time and wider view which facilitates removal of big and fixed uteri.
The demographic profile in our study population shows comparable data with regards to age, parity and body weight. Some studies show that the TLH group included younger patients with less body weight. ${ }^{12}$ Patients with severe medical disorders were more in the TLH group in our study. Similar observations have been made by other authors. ${ }^{12}$

Though many studies show that obesity and advanced age are not contraindications for laparoscopic surgery; it has still been found to influence patient selection and surgical option. $^{14-17}$

In our study the mean blood loss, average hospital stay and pain score were more in the abdominal group than the TLH group.

Likewise, the mean operating time and cost of surgery were more in TLH group compared to the abdominal group. Mario Malzoni et al reported that mean operating time for TLH was $136 \mathrm{~min}$ and TAH was $123 \mathrm{~min}$. The mean blood loss was $50+12$ in the TLH group (95\% CI 20-90) and $145 \mathrm{ml}+35$ in TAH group (95\% CI 60-255) $(\mathrm{p}<0.01){ }^{18}$ The mean hospital stay was $5.1+1.2$ in the TAH group (95\% CI 1-7) and $2.1+0.5$ in TLH group $(95 \%$ CI 1-5) $(\mathrm{p}<0.01)$. These results are similar to the results derived in our study. Other authors have also reported similar results and emphasized that the TLH approach has definite advantage over abdominal approach..$^{6,8,19}$

Two other studies have showed that the TLH approach may incur less expenditure than the abdominal approach as the average length of hospital stay is more in the abdominal approach. ${ }^{9,20}$ The perioperative and postoperative complications were seen more in the abdominal group vs. TLH group.

Similar observation has been made by Mario Malzoni et al and other authors. ${ }^{18,19,21,22}$

No patient in the TLH group required conversion to laparotomy in our study. Mario Malzoni et al also reported 0 conversion rate. Other studies have reported $4.4 \%$ and $22.4 \%$ conversion rates due to vascular complications, massive adhesions and obesity. ${ }^{18}$

1 patient in the TLH group in our study had a small hematoma over left iliac vessel which was managed conservatively while 2 patients in abdominal group had bladder injury in the TAH group. Tae Wook et al reported 1 case of great vessel injury in TLH group and 2 cases of ureteric injury and 1 bladder injury in the TAH group. ${ }^{19}$

Vault recurrence occurred in 3 patients in the TLH group and 1 patient in the abdominal group which was comparable. Mario Malzoni et al did not find significant difference in disease free survival while Tae Wook et al also reported no statistically significant difference 
between both groups with regards to disease free and overall survival. Obermair et al reported similar patterns of recurrence and overall survival among both groups in a retrospective study of 510 patients. ${ }^{23}$ Walker at al reported 3 yrs overall survival of $89 \%$ in TLH group and $89.9 \%$ in abdominal group from the LAP 2 study conducted by gynecologic oncologic group. ${ }^{24,25}$

Several authors including Manolitas et al have concluded that total laparoscopic hysterectomy with surgical staging is an effective approach with many added benefits. ${ }^{26}$

\section{CONCLUSION}

Morbidity is much less in laparoscopy route compare to open abdominal hysterectomy with equivalent survival.

Funding: No funding sources

Conflict of interest: None declared

Ethical approval: Not required

\section{REFERENCES}

1. American cancer society, cancer Facts \& Figures 1212. Available at: https://www.cancer.org/research /cancer-facts-statistics/all-cancer-facts-figures/ cancer-facts-figures-2020.html. Accessed on 02 May 2020.

2. Brinton LA, Berman ML, Mortel R, Twiggs LB, Barrett RJ, Wilbanks GD, et al. Reproductive, menstrual, and medical risk factors for endometrial cancer: results from a case-control study. Americ J Obstet Gynecol. 1992;167(5):1317-25.

3. Lader H, N. SEER Cancer Statistics Review. 19752008. 2011. Available at: https://seer.cancer.gov/ archive/csr/1975_2008/. Accessed on 25 May 2020.

4. Weiderpass E, Persson I, Adami HO, Magnusson C, Lindgren A, Baron JA. Body size in different periods of life, diabetes mellitus, hypertension, and risk of postmenopausal endometrial cancer (Sweden). Canc Cause Contr. 2000;11(2):185-92.

5. Childers JM, Surwit EA. Combined laparoscopic and vaginal surgery for the management of two cases of stage 1 endometrial cancer. Gynecol Oncol. 1992;4651.

6. Scribner DR, Mannel RS, Walker JL, Johnson GA. Cost analysis of laparoscopy versus laparotomy for early endometrial cancer. Gynecol Oncol. 1999;75(3):460-3.

7. Holub Z, Voracck J, Shomani A. A comparison of laparoscopic surgery with open procedure in endometrial cancer. Eur J Gynaecol Oncol. 1998;19;294-6.

8. Spirtos NM, Schlaerth JB, Gross GM, Spirtos TW, Schlaerth AC, Ballon SC. Cost and quality-of-life analyses of surgery for early endometrial cancer: laparotomy versus laparoscopy. Americ J Obstet Gynecol. 1996;174(6):1795-800.

9. Spirtos NM, Schlaerth JB, Spirtos TW, Schlaerth AC, Indman PD, et al. Laparoscopic bilateral pelvic and paraaortic lymph node sampoing: An evolving technique. Americ J Obstet Gynecol. 1995;173(1):105-11.

10. Eltabbakh GH. Effect of surgeon's experience on the surgical outcome of laparoscopic surgery for women with endometrial cancer, Gynaecol Oncol. 2000; 78:58-61.

11. Scribner Jr DR, Walker JL, Johnson GA, McMeekin SD, Gold MA, Mannel RS. Laparoscopic pelvic and paraaortic lymph node dissection: analysis of the first 100 cases. Gynecol Oncol. 2001;82(3):498-503.

12. Gary S. Leiserowitz, MD, Guibo Xing, PhD Arti Parikh-Patel, et al. Laparoscopic Versus Abdominal Hysterectomy for Endometrial Cancer. Int $\mathbf{J}$ Gynaecol Canc. 2009 Nov: 19(8):1370-6.

13. Eltabbakh GH, Shamonki MI, Moody JM, Garafano LL. Hysterectomy for obese women with endometrial cancer: laparoscopy or laparotomy? Gynecol Oncol. 2000;78(3):329-35.

14. Ghezzi F, Cromi A, Bergamini V, Uccella S, Beretta $\mathrm{P}$, Franchi M, et al. Laparoscopic management of endometrial cancer in nonobese and obese women; A consecutive series. J Minim Invasive Gynecol. 2006; 13, 269-275.

15. Scribner Jr DR, Walker JL, Johnson GA, McMeekin DS, Gold MA, Mannel RS. Laparoscopic pelvic and paraaortic lymph node dissection in the obese. Gynecol Oncol. 2002;84(3):426-30.

16. Holub Z, Jabor A, Bartos P, Eim J, Urbanek S, Pivovarnikova R. Laparoscopic surgery for enodometrial cancer: long- term results of a multicentric study. Eur J Gynaecol Oncol. 2002;23,305-10.

17. Scribner DR, Walker JL, Johnson GA, McMeekin SD, Gold MA, Mannel RS. Surgical management of early-stage endometrial cancer in the elderly: is laparoscopy feasible? Gynecol Oncol. 2001;83(3):563-8.

18. Malzoni M, Tinelli R, Cosentino F, Perone C, Rasile M, Iuzzolino D, et al. Total laparoscopic hysterectomy versus abdominal hysterectomy with lymphadenectomy for early-stage endometrial cancer: a prospective randomized study. Gynecol Oncol. 2009;112(1):126-33.

19. Kong TW, Lee KM, Cheong JY, Kim WY, Chang SJ, Yoo SC, et al. Comparison of laparoscopic versus conventional open surgical staging procedure for endometrial cancer. J Gynecol Oncol. 2010;21(2):106-11.

20. Gemignani ML, Curtin JP, Zelmanovich J, Patel DA, Venkatraman E, Barakat RR. Laparoscopic-assisted vaginal hysterectomy for endometrial cancer: clinical outcomes and hospital charges. Gynecol Oncol. 1999;73(1):5-11.

21. Kuoppala T, Tomas E, Heinonen PK. Clinical outcome and complications of laparoscopic surgery compared with traditional surgery la women with endometrial cancer Arch Gynaecol Obstet. 2004;270:25-30. 
22. Fram KM, Laparoscopically assisted vaginal hysterectomy versus abdominal hysterectomy in stage 1 endometrial cancer. Int J Gynaecol Cancer 2002; 12:57-61.

23. Obermair A, Manolitsas TP, Leung Y, Hammond IG, McCartney AJ. Total laparoscopic hysterectomy for endometrial cancer: patterns of recurrence and survival. Gynecol Oncol. 2004;92(3):789-93.

24. Walker JL, Piedmonte MR, Spirtos NM, Eisenkop SM, Schlaerth JB, Mannel RS, et al. Laparoscopy compared with laparotomy for comprehensive surgical staging of uterine cancer; Gynaecologic Oncology Group Study LAP2. J Clin Oncol 2009;27:5331-6.

25. Walker JL, Piedmonte MR, Spirtos NM, Eisenkop SM, Schlaerth JB, Mannel RS, et al. Recurrence and survival after random assignment to laparoscopy versus laparotomy for comprehensive surgical staging of uterine cancer: Gynecologic Oncology Group LAP2 Study. J Clinic Oncol. 2012;30(7):695.

26. Manolitsas TP, McCartney AJ. Total laparoscopic hysterectomy in the management of endometrial carcinoma. J Americ Assoc Gynecol Laparoscop. 2002;9(1):54-62.

Cite this article as: Bhattacharjee R, Dhungat NP, Sheth V. Comparative study between laparoscopic hysterectomy and abdominal hysterectomy for the treatment of early stage endometrial cancer. Int J Reprod Contracept Obstet Gynecol 2020;9:4526-30. 